\title{
PERANCANGAN ENTERPRISE ARCHITECTURE PADA PT VITAPHARM MENGGUNAKAN FRAMEWORK TOGAF
}

\author{
Ignatius Adrian Mastan ${ }^{1 *}$, Mario Stefanus ${ }^{2}$ \\ ${ }^{1,2}$ Program Studi Sistem Informasi, Fakultas Teknologi dan Desain \\ Universitas Bunda Mulia \\ Jalan Lodan Raya No. 2 Ancol, Jakarta Utara 14430 \\ *Corresponding Author: imastan@bundamulia.ac.id
}

\begin{abstract}
$P T$ Vitapharm is a leading cosmetic company in Indonesia that produces cosmetic products. In its operational activities, PT Vitapharm still has several obstacles in its business processes, one of the main problems is that some processes still use manual systems and have not yet integrated one process with another because there is no adequate information technology support. Thus, the business processes within the company have not been able to support the company to achieve organizational goals. Therefore, PT Vitapharm requires an Enterprise Architecture design so that the company's business goals can be achieved with the help of information technology. To solve the problems faced by PT Vitapharm can be completed by designing an Enterprise Architecture with the TOGAF framework. TOGAF framework was chosen because it can design and solve problems faced by PT Vitapharm. The stages of designing an Enterprise Architecture with the TOGAF framework start from the preliminary phase, requirements management, architecture vision, business architecture, information system architecture, technology architecture, opportunities and solutions, and migration planning. This study does not use the implementation governance and architecture change management stages. Research using the TOGAF framework produces an enterprise architecture design that can answer the needs of PT Vitapharm in order to adapt to the Information System/Information Technology strategic planning. The results of this study are designs that can be used by PT Vitapharm and become PT Vitapharm's reference in compiling business process improvements so that they can improve the company's internal business processes and can improve operational activities, and can achieve company goals.
\end{abstract}

Keywords: enterprise architecture, framework, TOGAF.

\footnotetext{
ABSTRAK

PT Vitapharm merupakan sebuah perusahaan kosmetik terkemuka di Indonesia yang memproduksi produk-produk kosmetik. Dalam kegiatan operasionalnya, PT Vitapharm masih memiliki beberapa kendala dalam proses bisnisnya, salah satunya permasalahan yang utama adalah beberapa proses masih menggunakan sistem manual dan belum terintegrasinya proses yang satu dengan proses lainnya karena
} 
belum adanya dukungan teknologi informasi yang memadai. Dengan demikian, maka proses bisnis di dalam perusahaan belum dapat mendukung perusahaan untuk mencapai tujuan organisasi. Oleh karena itu, PT Vitapharm membutuhkan perancangan Enterprise Architecture agar tujuan bisnis perusahaan dapat tercapai dengan bantuan teknologi informasi. Untuk mengatasi permasalahan yang dihadapi oleh PT Vitapharm dapat diselesaikan dengan perancangan Enterprise Architecture dengan framework TOGAF. Framework TOGAF dipilih karena dapat mampu merancang dan menyelesaikan permasalahan yang dihadapi oleh PT Vitapharm. Tahapan dari perancangan Enterprise Architecture dengan framework TOGAF dimulai dari tahap preliminary phase, requirement management, architecture vision, business architecture, information system architecture, technology architecture, opportunities and solution, dan migration planning. Di dalam penelitian ini tidak menggunakan tahap implementation governance dan architecture change management. Penelitian menggunakan framework TOGAF menghasilkan sebuah rancangan Enterprise Architecture yang dapat menjawab kebutuhan PT Vitapharm agar dapat menyesuaikan dengan perencanaan strategis Sistem Informasi/Teknologi Informasi. Hasil dari penelitian ini adalah perancangan yang dapat digunakan oleh PT Vitapharm dan menjadi acuan PT Vitapharm dalam menyusun perbaikan proses bisnis sehingga dapat memperbaiki proses bisnis internal perusahaan dan dapat meningkatkan kegiatan operasional, serta dapat mencapai tujuan perusahaan.

Kata kunci: arsitektur perusahaan, kerangka kerja, TOGAF.

\section{PENDAHULUAN}

Perkembangan teknologi informasi pada saat ini mempengaruhi banyak aspek. Salah satu aspek yang paling banyak mengalami dampak dari perkembangan teknologi adalah industri manufaktur. Industri menjadi salah satu sektor yang terkena dampak terhadap perkembangan teknologi informasi di era industri 4.0. Sektor industri dituntut agar dapat terus menyesuaikan diri serta mengoptimalkan proses bisnis yang ada di dalam organisasi agar dapat menghasilkan produk berkualitas tinggi dalam waktu yang singkat serta dapat mengikuti perkembangan teknologi informasi dan mendukung tujuan organisasi. Untuk dapat mendukung tercapainya tujuan perusahaan, sebuah organisasi memerlukan evaluasi ulang terhadap aktivitas dan proses baik internal maupun eksternal.

Dalam rangka mencapai sebuah keunggulan kompetitif, sebuah organisasi dapat menggunakan berbagai macam metode, salah satunya adalah Enterprise Architecture (EA). Enterprise Architecture merupakan sebuah gambaran atau blueprint suatu organisasi yang selaras antara visi dan misi organisasi dengan sistem informasi/teknologi informasi (Retnawati, 2018). Acuan baku dari perancangan Enterprise Architecture adalah Enterprise Architecture Framework yang terdiri dari Enterprise Architecture Planning (EAP), The Open Group Architecture Framework (TOGAF), Zachman Framework, Federal Enterprise Architecture Framework (FEAF), Department of Defense Architecture Framework 
(DODAF), dan Gartner (Azizi dan Mahmudy, 2017). Masing-masing kerangka kerja tersebut memliki tujuan yang sama yaitu menjembatani serta menyelaraskan antara proses bisnis serta sistem informasi/teknologi informasi dalam memenuhi dan mencapai tujuan bisnis perusahaan (Kappelman and Zachman, 2015).

PT Vitapharm merupakan industri yang bergerak pada bidang manufaktur produk kosmetik dengan produk utamanya adalah Viva Kosmetik. Viva Kosmetik merupakan produk kecantikan yang sudah sangat populer digunakan masyarakat di Indonesia. Produk Viva Kosmetik yang dihasilkan oleh PT Vitapharm tidak terlepas dari alur proses industri manufaktur yang kompleks. Pada proses bisnis di PT Vitapharm, masih terdapat beberapa permasalahan, salah satunya adalah sistem yang masih manual dan belum terintegrasi satu sama lain karena masih belum didukung secara maksimal oleh penggunaan teknologi yang ada. Oleh sebab itu, industri manufaktur ini membutuhkan perancangan Enterprise Architecture (EA) agar visi misi dan tujuan bisnis perusahaan dapat tercapai.

Berdasarkan permasalahan yang dialami oleh PT Vitapharm, maka dibuatlah sebuah perancangan Enterprise Architecture dengan menggunakan framework TOGAF. Framework TOGAF dipilih karena merupakan kerangka kerja dan panduan yang dianggap mampu dalam menyelesaikan masalah tersebut. Framework TOGAF merupakan hasil pengembangan The Open Group's Architecture Framework pada tahun 1995 yang sekarang sudah dilengkapi oleh Architecture Development Method (ADM) yang terdiri dari delapan fase utama untuk pengembangan dan pemeliharaan technical architecture dari organisasi (Rizky et al., 2017).

Dengan demikian, penelitian ini akan menghasilkan sebuah blueprint Enterprise Architecture dengan menggunakan framework TOGAF, sehingga dapat meningkatkan performa proses bisnis internal di dalam PT Vitapharm dan menyelaraskan strategi sistem informasi/teknologi informasi dengan kebutuhan dan tujuan bisnis perusahaan. Dengan memanfaatkan hasil penelitian ini diharapkan dapat menyelesaikan permasalahan yang dihadapi oleh PT Vitapharm.

\section{TINJAUAN PUSTAKA}

\section{Enterprise Architecture}

Menurut Surendro (2009) architecture merupakan suatu perencanaan yang diwujudkan dengan model dan gambar dari bagian/komponen dari sesuatu dengan berbagai sudut pandang. Sedangkan mengenai Enterprise Architecture, Surendro (2009) menyatakan bahwa Enterprise Architecture merupakan kumpulan prinsip, metode, dan model yang bersifat masuk akal yang digunakan untuk mendesain dan merealisasikan sebuah struktur organisasi enterprise, struktur organisasi, sistem informasi, dan sistem infrastrukturnya.

Enterprise Architecture diperlukan karena merupakan sebagai dasar sistem organisasi yang terdiri dari sekumpulan komponen yang memiliki hubungan satu sama lainnya serta memiliki keterhubungan dengan lingkungan sistem, dan memiliki aturan untuk perancangan dan evaluasi. Enterprise Architecture adalah blueprint organisasi yang menentukan bisnis, informasi, dan teknologi yang digunakan agar tercapai misi organisasi (The Open Group, 2009). 
Berdasarkan definisi di atas, maka dapat disimpulkan Enterprise Architecture merupakan perancangan proses bisnis dan teknologi (hardware, software, dan network) di setiap organisasi maupun perusahaan yang kemudian diintegrasikan dengan misi, sasaran, dan tujuan organisasi untuk menjalankan proses bisnis organisasi.

Menurut Surendro (2009) dalam menyusun Arsitektur Enterprise terdapat empat komponen/domain utama, yaitu:

1. Arsitektur Bisnis yang menggambarkan strategi, maksud, fungsi, proses, informasi, dan aset bisnis yang penting untuk memberikan layanan bagi masyarakat, bisnis, pemerintah, dan sebagainya.

2. Arsitektur Informasi, yaitu kumpulan kebutuhan bisnis perusahaan, informasi, satuan proses, dan penyatuan yang berbisnis serta aturan untuk memilih, membangun, dan memelihara informasi tersebut.

3. Arsitektur Teknologi, yaitu suatu pendekatan dalam menjelaskan struktur dan hubungan teknologi perusahaan saat ini serta di masa depan untuk memaksimalkan nilai dalam teknologi tersebut.

4. Arsitektur Aplikasi, yaitu sebuah proses dalam arsitektur enterprise yang memusatkan pada pengembangan dan penerapan sebuah solusi atau layanan yang sedang diciptakan untuk organisasi tersebut.

\section{Enterprise Architecture Planning (EAP)}

Menurut Putri et al. (2020) Enterprise Architecture Planning (EAP) merupakan suatu pendekatan yang dibuat oleh Steven H. Spewak untuk membangun arsitektur enterprise berdasarkan data dan bisnis. Enterprise Architecture Planning (EAP) adalah proses mendefinisikan arsitektur dalam penggunaan informasi untuk mendukung bisnis dan rencana mengimplementasikan arsitektur tersebut. Enterprise Architecture Planning (EAP) memberikan gambaran praktis dalam membuat arsitektur dari dua baris dan tiga kolom pertama kerangka kerja Zachman. Kerangka kerja Zachman merupakan kerangka kerja untuk menggambarkan hubungan antara komponen enterprise terhadap level arsitektur yang menjadi tujuan utama bagi yang berkepentingan dengan Enterprise Architecture. Hubungan antara kerangka kerja Zachman dan Enterprise Architecture Planning (EAP) adalah proses mendefinisikan dua level atas kerangka kerja Zachman. Sehingga jika dipetakan ke dalam kerangka kerja Zachman, Enterprise Architecture Planning (EAP) akan berada di baris pertama dan baris kedua yang merupakan perspektif perencana dan pemilik. Sedangkan aspek yang dibahas dalam Enterprise Architecture Planning (EAP) berada pada tiga kolom dari kerangka kerja Zachman, yaitu meliputi data, fungsi, dan jaringan dari arsitektur sistem informasi. Enterprise Architecture Planning (EAP) memiliki tujuh komponen utama yang menunjukkan tahapan untuk menentukan dan merencanakan implementasi dari arsitektur sistem informasi. Tujuh komponen utama dari Enterprise Architecture Planning (EAP) ini dikelompokkan menjadi empat lapisan seperti terlihat pada Gambar 1. 


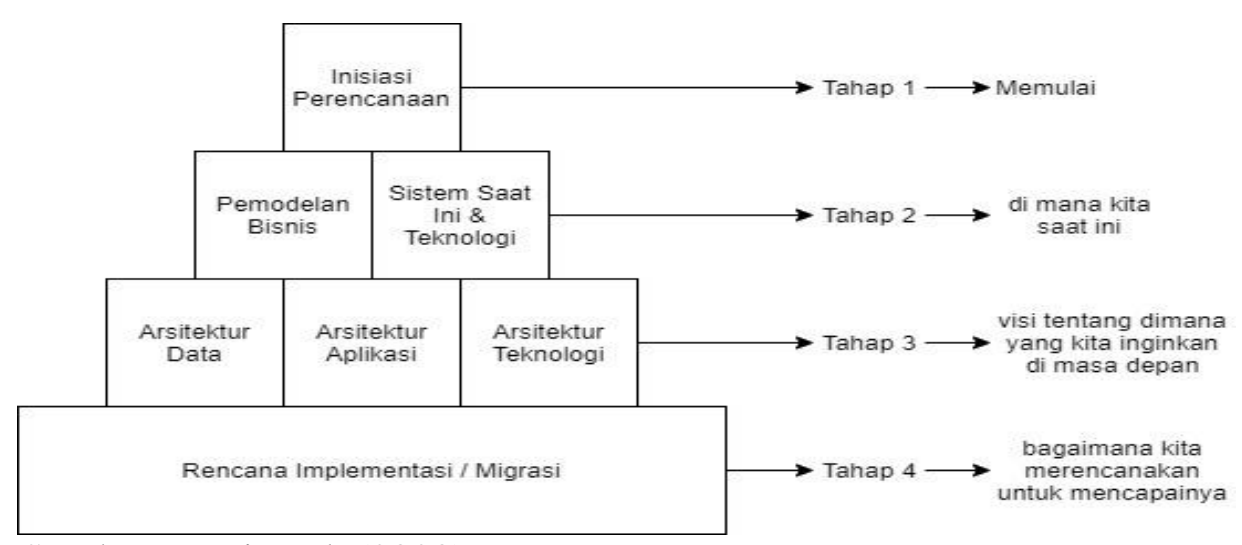

Sumber: Putri et al. (2020)

\section{Gambar 1}

Komponen dan Lapisan Enterprise Architecture Planning (EAP)

\section{The Open Group Architecture Framework (TOGAF)}

TOGAF berasal dari kerangka kerja AS DOD, dan tujuan utamanya adalah untuk meningkatkan efisiensi bisnis organisasi dengan menyediakan metodologi yang memungkinkan untuk pengembangannya. TOGAF mampu memberikan implementasi sederhana, dan keselarasan yang sangat baik antara bisnis dan teknologi informasi. Kerangka kerja ini terdiri dari enam komponen: metode pengembangan arsitektur/Architecture Development Method (ADM), kerangka konten arsitektur, model referensi, pedoman dan teknik ADM, kontinum perusahaan, dan kerangka kemampuan perusahaan. ADM merupakan komponen penting, karena bertanggung jawab untuk mengembangkan arsitektur perusahaan dengan menangani persyaratan bisnis.

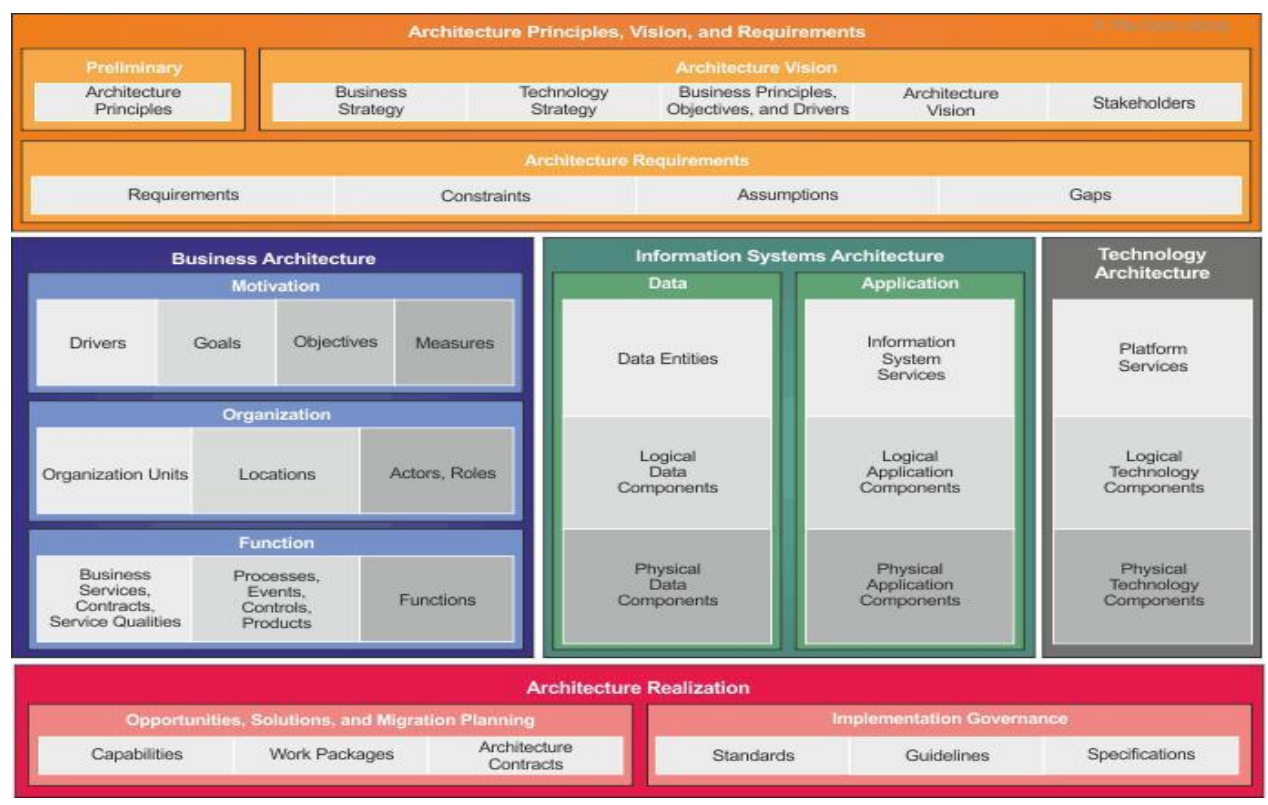

Sumber: Alshamari (2017)

Gambar 2

The Open Group Architecture Framework (TOGAF) Components 
Dapat disimpulkan bahwa semua kerangka kerja Enterprise Architecture saat ini memiliki tujuan yang sama, yaitu untuk menciptakan Enterprise Architecture yang meningkatkan keselarasan sumber daya bisnis dan teknologi informasi. Tujuan ini dapat menyebabkan pengurangan kompleksitas sistem dan memanfaatkan sumber daya organisasi dalam pendekatan yang efisien.

\section{TOGAF Architecture Development Method (ADM)}

Menurut Surendro (2009) TOGAF memberikan metode yang detail mengenai bagaimana membangun, mengelola, dan mengimplementasikan Enterprise Architecture dan sistem informasi yang disebut dengan Architecture Development Method (ADM), di mana ADM merupakan hasil dari kerja sama praktisi arsitektur dalam Open Group Architecture Forum. ADM merupakan metode generik yang berisikan sekumpulan aktivitas yang merepresentasikan progresi dari setiap fase ADM dan model arsitektur yang digunakan dan dibuat selama tahap pengembangan Enterprise Architecture.

Menurut Irmayanti dan Permana (2018) TOGAF adalah kerangka kerja arsitektur yang digunakan sebagai alat untuk membantu dalam penerimaan, produksi, penggunaan, dan pemeliharaan arsitektur perusahaan. Hal ini didasarkan pada model proses berulang yang didukung oleh praktek terbaik dan satu set aset arsitektur yang telah ada dan yang dapat digunakan kembali. TOGAF 9 pertama kali dipublikasikan pada Januari 2009. TOGAF 9 dapat digunakan untuk mengembangkan berbagai jenis perusahaan dengan arsitektur yang berbeda. TOGAF melengkapi dan dapat digunakan bersama dengan kerangka kerja lain yang lebih terfokus pada kiriman khusus untuk sektor vertikal tertentu seperti pemerintah, telekomunikasi, manufaktur, pertahanan, dan keuangan. Kunci utama TOGAF adalah Architecture Development Method (ADM) yang digunakan untuk mengembangkan arsitektur enterprise yang dapat memenuhi kebutuhan bisnis. TOGAF ADM merupakan metode yang fleksibel yang dapat mengautentifikasi berbagai macam teknik pemodelan yang digunakan dalam perancangan, karena metode ini bisa disesuaikan dengan perubahan dan kebutuhan selama perancangan dilakukan.

Prinsip pengembangan enterprise dengan menggunakan metodologi TOGAF ADM terdiri dari tiga bagian yaitu:

1. Prinsip-prinsip enterprise, mendukung keputusan bisnis di seluruh bagian organisasi/perusahaan.

2. Prinsip-prinsip teknologi informasi, mengarahkan penggunaan sumber daya teknologi informasi di seluruh bagian organisasi/perusahaan.

3. Prinsip-prinsip arsitektur, mengembangkan arsitektur proses organisasi/ perusahaan, dan arsitektur implementasinya. Prinsip ini dipengaruhi oleh rencana organisasi/perusahaan, strategi, faktor pasar, sistem, dan teknologi yang ada dalam organisasi/perusahaan.

Menurut The Open Group (2009) ADM memiliki sepuluh fase seperti terlihat pada Gambar 3. 


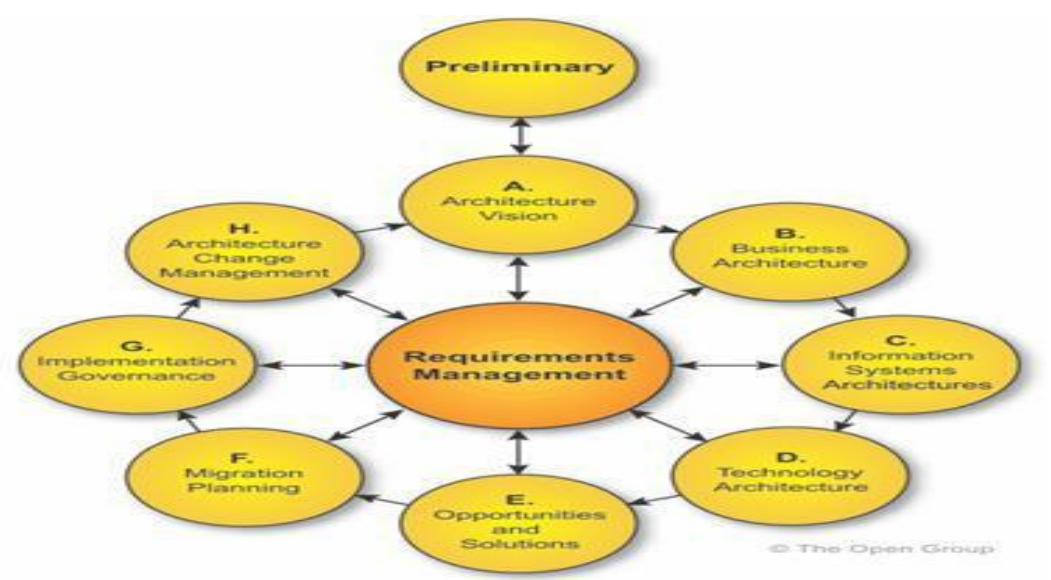

Sumber: The Open Group (2009)

\section{Gambar 3}

TOGAF ADM

\section{METODE PENELITIAN}

Penelitian ini dilakukan dengan menggunakan prosedur atau langkah-langkah seperti terlihat pada Gambar 4.

1

- Analisa Proses Bisnis Berialan

2

- Identifikasi Masalah

3

- Studi Literatur

4

- Merancang Enterprise Architecture dengan Framework TOGAF

5

- Blueprint Enterprise Architecture

\section{Gambar 4}

\section{Prosedur Penelitian}

Prosedur penelitian dapat dijabarkan sebagai berikut:

1. Analisa Proses Bisnis Berjalan, pada tahapan ini peneliti melakukan observasi terhadap proses bisnis yang terjadi pada PT Vitapharm sehingga dapat mengetahui proses bisnis yang sedang terjadi di dalam kegiatan operasional PT Vitapharm.

2. Identifikasi Masalah, pada tahapan ini merumuskan masalah yang menjadi topik penelitian dengan menggunakan framework TOGAF untuk menyelesaikan permasalahan yang dihadapi oleh PT Vitapharm.

3. Studi Literatur, menggunakan studi literatur yang terkait dengan topik yang berhubungan dengan masalah dalam penelitian ini. Studi literatur diperoleh dari 
paper, jurnal, buku, atau penelitian yang serupa. Dengan demikian dapat menjadi panduan dan pedoman dalam melakukan penelitian ini.

4. Merancang Enterprise Architecture dengan Framework TOGAF, merancang enterprise architecture yang dapat mengintegrasikan proses bisnis dengan penggunaan teknologi informasi untuk dapat mencapai tujuan bisnis perusahaan.

5. Blueprint Enterprise Architecture, hasil akhir dari penelitian ini adalah memberikan blueprint rancangan enterprise architecture yang dapat membantu PT Vitapharm untuk menyelesaikan permasalahan sehingga dapat membantu PT Vitapharm mencapai tujuan perusahaan dengan bantuan penggunaan teknologi informasi.

\section{HASIL PENELITIAN DAN PEMBAHASAN}

\section{Teknik Perancangan}

Teknik perancangan Enterprise Architecture dengan menggunakan framework TOGAF yang dimulai dari preliminary phase, requirements management, architecture vision, business architecture, information systems architectures, technology architecture, opportunities \& solutions, sampai dengan migration planning untuk diterapkan pada PT Vitapharm. Proses bisnis yang berjalan di PT Vitapharm seperti terlihat pada Gambar 5.

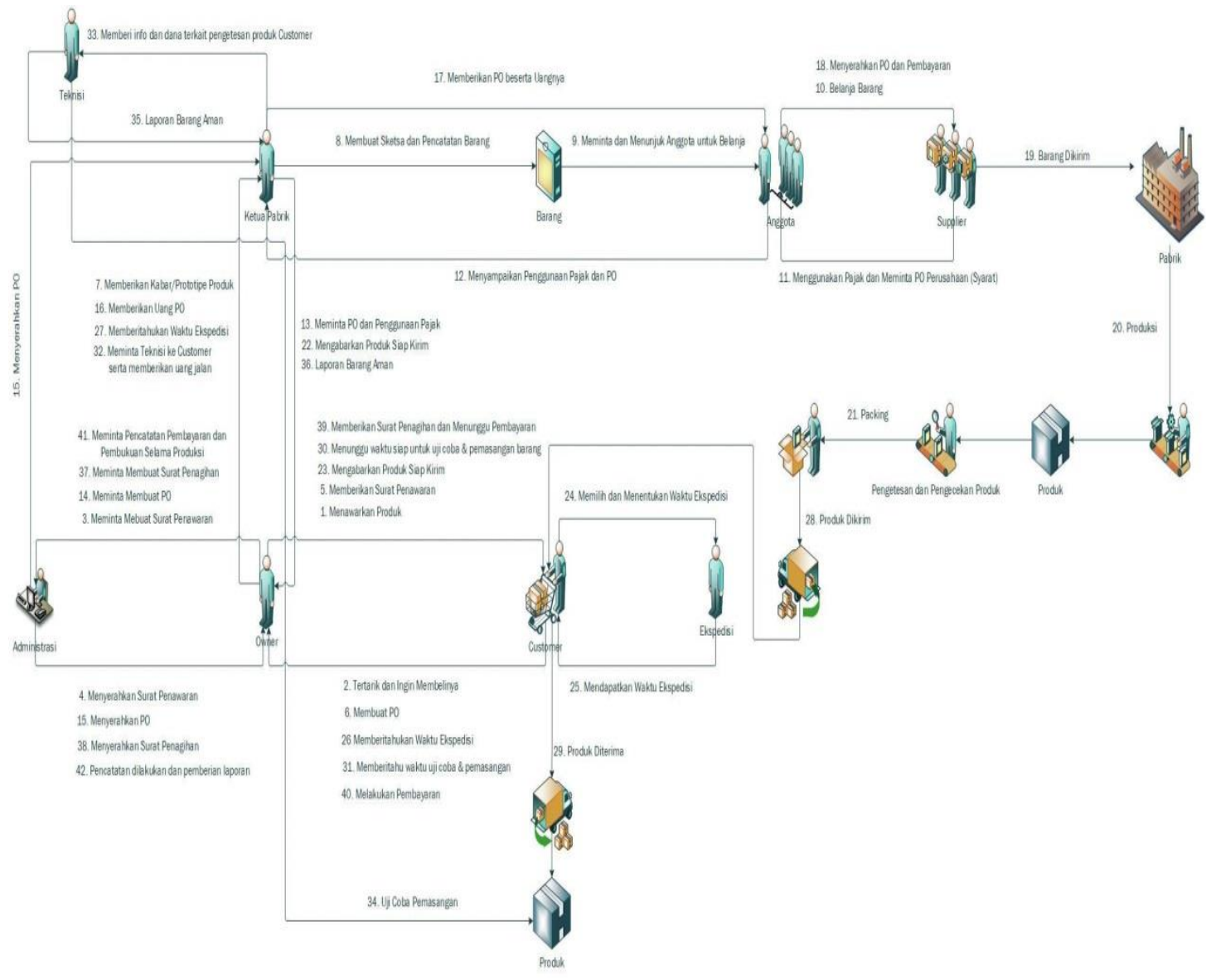

Gambar 5

Proses Bisnis PT Vitapharm yang Sedang Berjalan 
Data Dissemination Diagram pada Gambar 6 menggambarkan hubungan layanan pada PT Vitapharm, aplikasi, dan data. Pada Aplikasi Keuangan terdapat data pendapatan, data pengeluaran, dan data user. Pada Aplikasi Pengelolaan Aset terdapat data aset, data anggaran, dan data user. Pada Aplikasi Penjadwalan Produksi terdapat data barang, data pesanan, data jadwal produksi, dan data user. Pada Aplikasi Sales \& Marketing terdapat data promosi, data target, data penjualan, dan data user.

Pada Aplikasi Kepegawaian terdapat data pegawai, data absensi, data penggajian, dan data user. Pada Aplikasi Inventori terdapat data purchase order, data pembayaran, data penjualan, data barang, data supplier, data pembelian, data user. Pada Aplikasi Administrasi Laporan terdapat data laporan dan data user. Pada Website perusahaan terdapat data user dan data website.

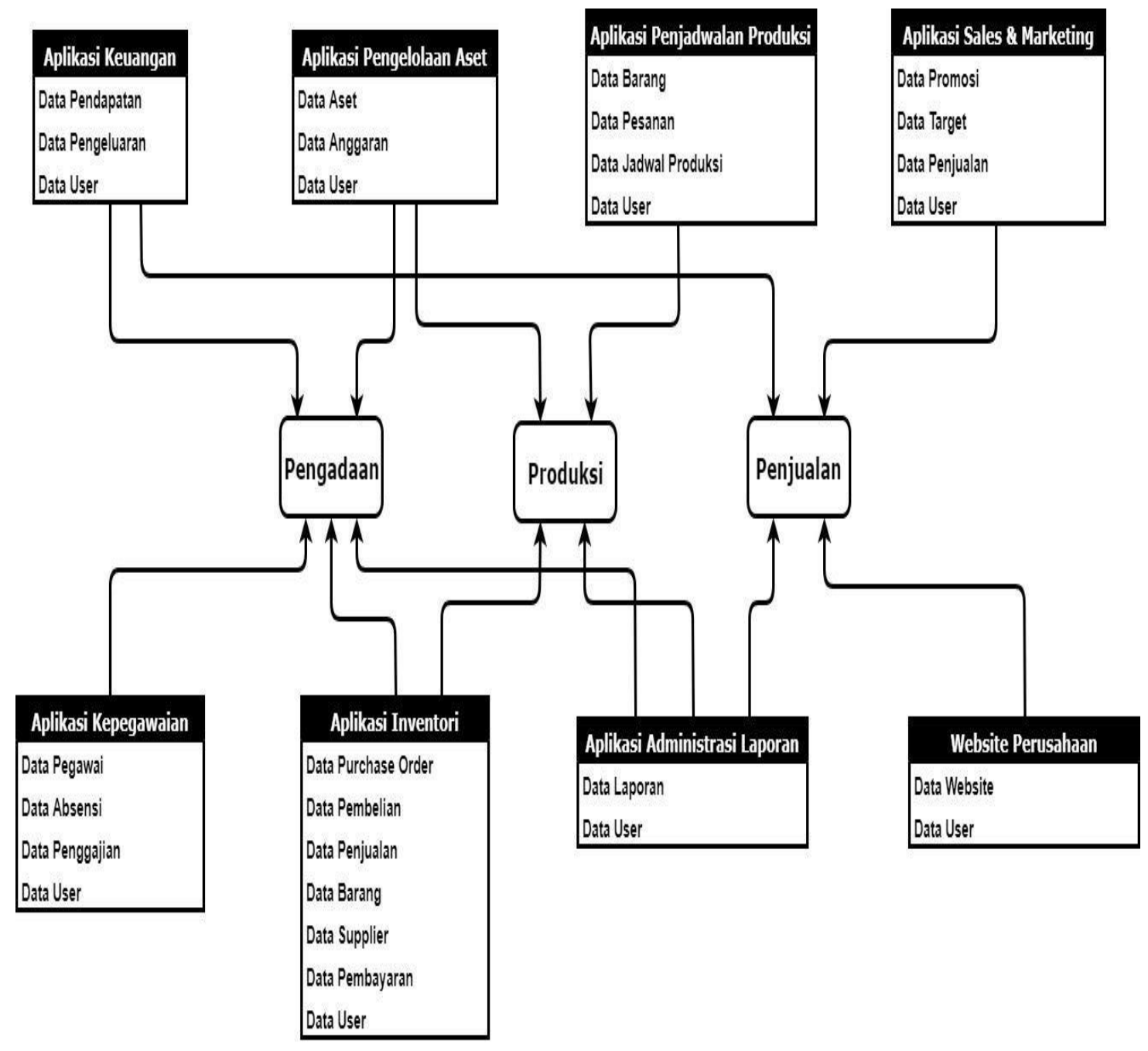

Gambar 6

Data Disemmination Diagram 
Platform Decomposition Diagram

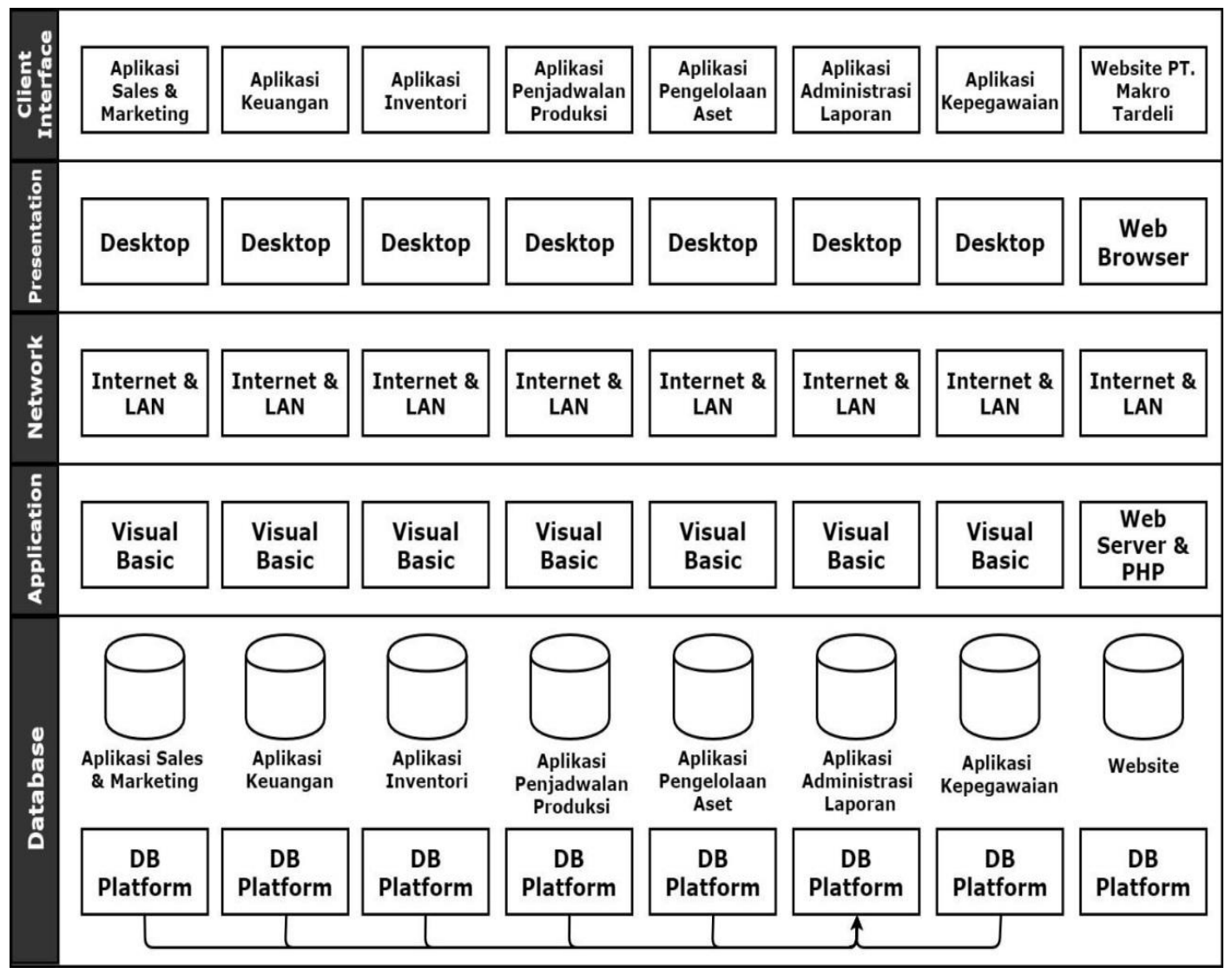

\section{Gambar 7}

\section{Platform Decomposition Diagram}

Gambar 7 Platform Decomposition Diagram menggambarkan sistem secara menyeluruh yang diusulkan. Terdapat lima level yaitu Client Interface, Presentation, Network, Application, dan Database. Pada Client Interface, user internal dapat mengakses baik menggunakan internet maupun LAN, sedangkan user external (khusus hanya pada bagian website) dapat mengakses melalui web browser menggunakan internet ataupun LAN. Pengembangan aplikasi menggunakan bahasa pemrograman Visual Basic, sedangkan website perusahaan menggunakan PHP (Hypertext Preprocessor). Kemudian bahasa pemograman yang digunakan akan mengambil dari data storage pada setiap aplikasi, kecuali untuk bagian aplikasi Administrasi Laporan yang mengambil setiap data dari masing-masing aplikasi (website tidak termasuk).

Aplikasi Sales \& Marketing akan mengambil data dari storage Sales \& Marketing. Aplikasi Keuangan akan mengambil data dari storage Keuangan. Aplikasi Inventori akan mengambil data dari storage Inventori. Aplikasi Penjadwalan Produksi akan mengambil data dari storage Penjadwalan Produksi. Aplikasi Pengelolaan Aset akan mengambil data dari storage Pengelolaan Aset. Aplikasi Kepegawaian akan mengambil data dari storage Kepegawaian. Website perusahaan akan mengambil data dari storage website perusahaan. 


\section{Roadmap Aplikasi}

Pada bagian ini akan menjelaskan tentang arahan pengembangan aplikasi yang strategis. Berikut Gambar 8 menjelaskan tentang roadmap aplikasi.

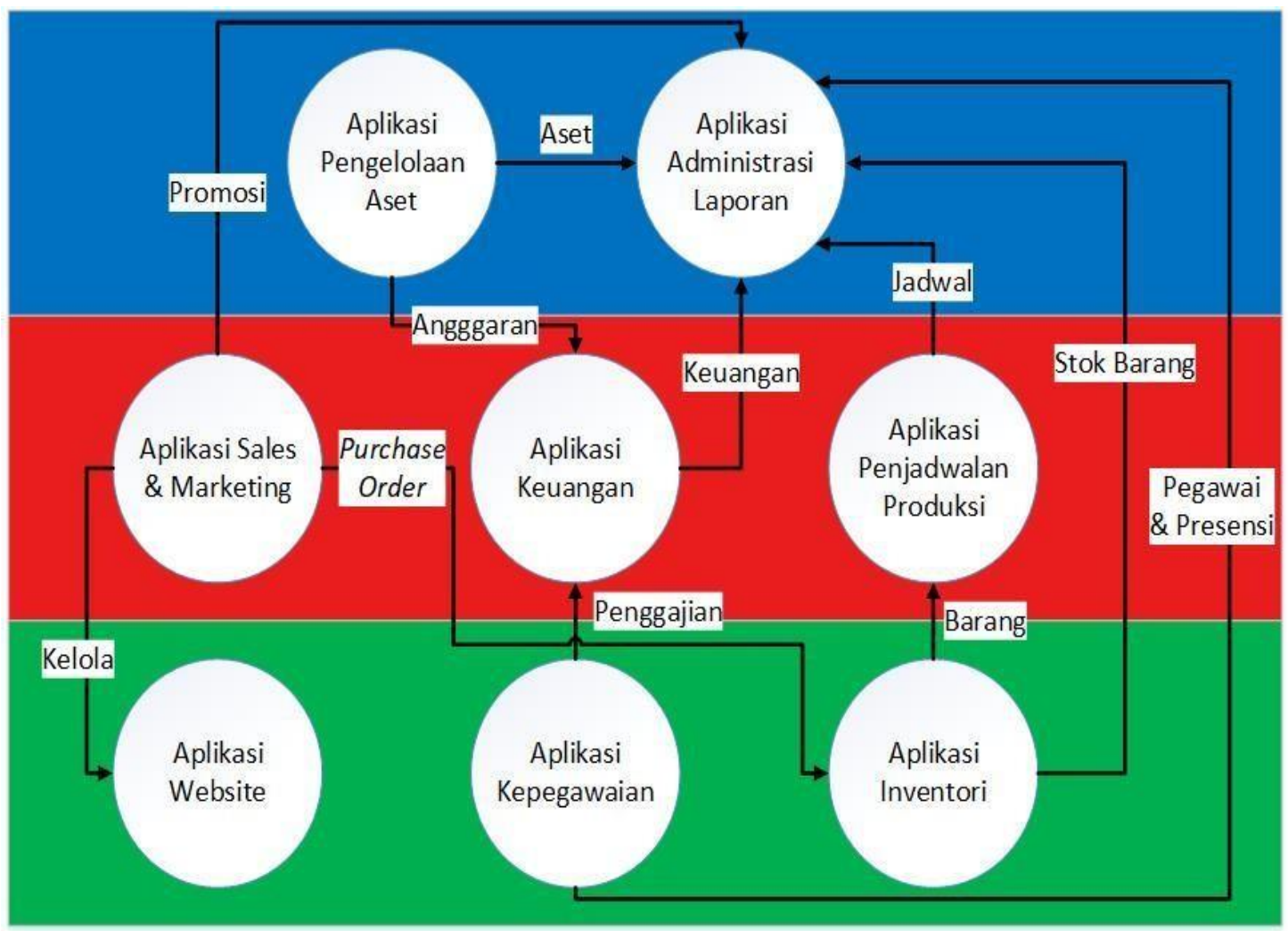

Gambar 8

\section{Roadmap Aplikasi}

*) Keterangan

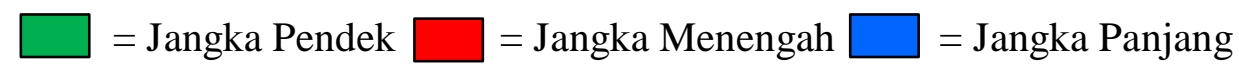

Pada Gambar 8 terdapat tiga jenis urutan implementasi, yaitu jangka pendek, jangka menengah, dan jangka panjang. Pada jangka pendek terdapat aplikasi website, aplikasi kepegawaian, dan aplikasi inventori. Aplikasi website untuk melakukan promosi produk perusahaan dan menjadikannya sebuah company profile. Aplikasi kepegawaian untuk mengelola data karyawan, presensi, serta penggajiannya. Aplikasi inventori untuk melakukan pengelolaan stok barang.

Pada urutan jangka menengah terdapat aplikasi Sales \& Marketing, aplikasi keuangan, aplikasi penjadwalan produksi. Aplikasi Sales \& Marketing untuk melakukan pecatatan promosi kepada customer dan pembuatan purchase order. Aplikasi keuangan untuk pengelolaan keuangan baik pendapatan, pengeluaran, maupun buku besar. Aplikasi penjadwalan produksi untuk pembuatan jadwal 
terkait produksi serta menyeimbangkan antara bahan baku, sumber daya, dan waktu agar dapat terselesaikan tepat waktu.

Pada urutan jangka panjang terdapat dua aplikasi, yaitu aplikasi pengelolaan aset dan aplikasi administrasi laporan. Aplikasi pengelolaan aset untuk monitoring aset yang dimiliki perusahaan baik dalam nilai aset ataupun penyusutan aset tersebut, serta dapat melakukan pembuatan anggaran untuk pengadaan aset baru apabila terdapat aset yang perlu diganti ataupun penambahan. Aplikasi administrasi laporan untuk mengintegrasikan seluruh laporan aplikasi yang kemudian akan dilakukan pengecekan oleh owner sebagai bahan pertimbangan dalam menentukan tujuan perusahaan yang ingin dicapai.

\section{Perencanaan Target Implementasi}

Perencanaan target implementasi pembuatan aplikasi PT Vitapharm menggunakan metode SDLC (System Development Life Cycle). Metode ini terbagi menjadi 4 tahapan, yang terdiri dari:

1. Perencanaan Sistem

Pada tahapan ini akan dilakukan pendefinisian masalah dan menentukan tujuan sistem.

2. Analisis Sistem

Pada tahap ini akan dilakukan analisis sistem berjalan dan usulan dengan cara mengidentifikasi masalah serta mendefinisikan kebutuhan informasi.

3. Desain Sistem

Pada tahap ini akan dilakukan pembuatan pemodelan proses, pemodelan database, dan interface.

4. Implementasi Sistem

Pada tahapan ini akan dilakukan pembuatan sistem yang terdiri dari coding, testing, dan revisi.

\section{SIMPULAN}

Proses bisnis PT Vitapharm masih belum mengoptimalkan pemanfaatan sistem informasi dan teknologi informasi sehingga penelitian ini dibuat untuk merancang Enterprise Arhcitecture dalam rangka menyelaraskan strategi bisnis dengan sistem informasi dan teknologi informasi. Perancangan Enterprise Architecture menggunakan framework TOGAF dengan metodologi ADM (Architecture Development Method).

Pengelolaan data pada PT Vitapharm masih dilakukan secara manual. Oleh karena itu penelitian ini melakukan perancangan Enterprise Architecture dengan memaksimalkan penggunaan sistem informasi dan teknologi informasi agar sistem dapat bekerja secara optimal dan integrasi data akan lebih meningkat, sehingga dapat membuat proses bisnis PT Vitapharm semakin membaik.

Perancangan Enterprise Architecture pada proses bisnis PT Vitapharm diharapkan dapat meningkatkan pelayanan, khususnya pada internal stakeholder, sehingga mempermudah dalam mencapai tujuan perusahaan dalam meningkatkan profit perusahaan. 


\section{SARAN}

Sistem yang akan dibangun hendaknya dibuat secara bertahap dan harus sesuai dengan kebutuhan utama PT Vitapharm. Dalam melakukan implementasi perancangan Enterprise Architecture diperlukan dukungan dari seluruh pihak dari PT Vitapharm demi keberhasilan dan dapat mencapai target yang diinginkan. PT Vitapharm perlu melakukan evaluasi dalam rangka penyesuaian antara sistem lama ke sistem baru saat implementasi Enterprise Architecture.

\section{DAFTAR PUSTAKA}

Alshamari, Bandar M. 2017. Enterprise Architecture Frameworks: A Critique Review from a Security Perspective. International Journal of Computer Applications, Vol. 174, No. 5, pp. 9-15.

Azizi, Fakri Fandi Nur dan Mahmudy, Wayan Firdausi. 2017. Mengukur Performa Enterprise Architecture Framework Menggunakan Fuzzy Tsukamoto. Jurnal Ilmu Komputer dan Teknologi Informasi, Vol. 8, No. 2, pp. 54-58.

Irmayanti, D. dan B. Permana. 2018. Perencanaan Arsitektur Enterprise Sistem Informasi Disnakersostrans Kabupaten Purwakarta Menggunakan TOGAF. Jurnal Teknologi Rekayasa, Vol. 3, No. 1, https://doi.org/10.31544/jtera.v3. i1.2018.17-28.

Kappelman, Leon A. and Zachman, John A. 2015. The Enterprise and Its Architecture: Ontology \& Challenges. Journal of Computer Information System, Vol. 53, Issue 4, pp. 87-95.

Putri, S. M., U. Hayati, dan R. Dzulkarnaen. 2020. Perancangan Arsitektur Electronic Medical Record (EMR) Menggunakan Metode Enterprise Architecture Planning (EAP) Arsitektur Enterprise. Journal of Information Technology (JOINT), Vol. 2, No. 1, pp. 25-30.

Retnawati, Lestari. 2018. Perancangan Enterprise Architecture Menggunakan TOGAF di Universitas ABC. Jurnal Iptek, Vol. 22, No. 1, pp. 13-20.

Rizky, Nela, Fitroh, dan Firmansyah, Asep Fajar. 2017. Perencanaan Arsitektur Enterprise Menggunakan TOGAF ADM Versi 9 (Studi Kasus: Bimbel Salemba Group). Jurnal Sistem Informasi, Vol. 10, No. 1, pp. 11-20.

Surendro, K. 2009. Pengembangan Rencana Induk Sistem Informasi. Informatika, Bandung.

The Open Group. 2009. TOGAF Version 9.1, The Open Group, San Fransisco. 